\title{
PReS-FINAL-2048: Treatment with methotrexate plus leflunomide for juvenile idiopathic arthritis
}

\author{
E Quesada-Masachs", C Modesto \\ From 20th Pediatric Rheumatology European Society (PReS) Congress \\ Ljubljana, Slovenia. 25-29 September 2013
}

\section{Introduction}

Methotrexate (MTX) is the agent of first choice for the treatment of children with Juvenile Idiopathic Arthritis (JIA). Leflunomide (LFN) has demonstrated to be an effective alternative to MTX. There is a lack of evidence regarding the advantages of combined treatment of MTX plus LFN in JIA.

\section{Objectives}

To evaluate the safety and effectiveness of the combined therapy with Methotrexate (MTX) and Leflunomide (LFN) in patients with Juvenile Idiopathic Arthritis (JIA) in clinical practice.

\section{Methods}

We conducted a retrospective descriptive study of patients with JIA visited in a single Unit of Pediatric Rheumatology who had been treated with the combination of MTX plus LFN. All patients were classified according to the International League of Associations for Rheumatology (ILAR) criteria. Included data were: demographics, JIA subtype, reason for starting combined treatment, time on treatment, withdrawals, causes of discontinuation, efficacy and safety (both assessed at baseline and every 6 months during 2 years of treatment). Safety was evaluated analyzing adverse events (AE) based on clinical and physical findings and laboratory values. Ocular effectiveness was assessed grading uveitis according to the Standardization of Uveitis Nomenclature Working Group (SUN) recommendations. Articular effectiveness was assessed by means of: pediatric core set variables with exception of C-HAQ, Protein-C-reactive, JADAS scores 10, 27 and 71, and applying the criteria of minimal disease activity, $30 \%$ improvement, inactivity and remission.

Rheumatology, Hospital Universitario Vall d'Hebron, Barcelona, Spain

\section{Results}

Nineteen patients ( 16 female, 3 male) were included: 12 oligoarthritis $(63 \%), 4$ polyarthritis $(21 \%), 2$ psoriatic arthritis (11\%) and 1 undifferentiated arthritis (5\%). The mean age at diagnosis was 57 months (4.75 years $\pm 3.65)$ and at initiation of combined treatment was 112 months $(9.37$ years \pm 4.12 ). The mean duration of MTX+LFN treatment was 28.6 months \pm 31.6 (range 5-144). An improvement was observed in each variable studied. JADAS scores had improved a $60 \%$ at last follow up compared to the baseline. The best rates of improvement were observed at 18 months of treatment: $91.7 \%$ improved at least $30 \%, 83.3 \%$ met criteria for minimal disease activity, $83.3 \%$ for inactivity and $66.7 \%$ for clinical remission. Eight children had uveitis and all of them were in clinical remission according to the SUN criteria at last follow up. Overall, $28 \mathrm{AE}$ were reported. There were no serious AE. The most frequently reported $\mathrm{AE}$ was upper respiratory tract infection. One of the two DMARD was stopped in 11 patients (58\%) due to AE in 4 children, inefficacy or loss of efficacy in 3 and clinical remission in 4. Gastrointestinal intolerance was the more common cause of discontinuation of one of the two DMARD. Among patients who withdrew the combined treatment 4 switched to anti-TNF therapy and 7 continued monotherapy with MTX or LFN. Eight children are still on MTX plus LFN.

\section{Conclusion}

In our patients with JIA the combined therapy of MTX plus LFN was well-tolerated and proved to be effective. Most of the patients experienced a substantial improvement either articular or ocular. AE were generally mild. LFN plus MTX could be a safe and effective alternative for patients with JIA who do not respond to MTX or LFN in monotherapy. 


\section{Disclosure of interest}

None declared.

Published: 5 December 2013

doi:10.1186/1546-0096-11-S2-P61

Cite this article as: Quesada-Masachs and Modesto: PReS-FINAL-2048:

Treatment with methotrexate plus leflunomide for juvenile idiopathic arthritis. Pediatric Rheumatology 2013 11(Suppl 2):P61.

Submit your next manuscript to BioMed Central and take full advantage of:

- Convenient online submission

- Thorough peer review

- No space constraints or color figure charges

- Immediate publication on acceptance

- Inclusion in PubMed, CAS, Scopus and Google Scholar

- Research which is freely available for redistribution 